The BDJ News section accepts items that include general news, latest research and diary events that interest our readers. Press releases or articles may be edited, and should include a colour photograph if possible. Please direct your correspondence to the News Editor, Arveen Bajaj at the BDJ, 64 Wimpole Street WIG 8YS or by email to bdj@bda.org

\section{GDC fees agreed}

The General Dental Council has agreed new registration fee levels for 2005. Subject to Privy Council approval, fees in 2005 for dentists will be $£ 396$ for the retention fee, while first registration is $£ 33$ per month or part thereof from the first month in which the entry is made until 31 December of that year.

The temporary registration fee is $£ 396$ while the restoration fee is $£ 100$. The new fees mean a retention fee increase of $€ 8(2 \%)$ which the Council claims will help it deal with any unpredicted increases in expenditure, and reduce any future increases.

The GDC also looked again at the issue of a discounted fee for over $65 \mathrm{~s}$, and confirmed that that there will be no discounts for particular groups of registrants, including dentists on the Keeping in Touch with Dentistry Scheme (KITS) and dentists over 65. This will also apply to dentists who hold temporary registration with the Council who, from next year, will pay the same as those with full registration.

\section{Tradition still going strong}

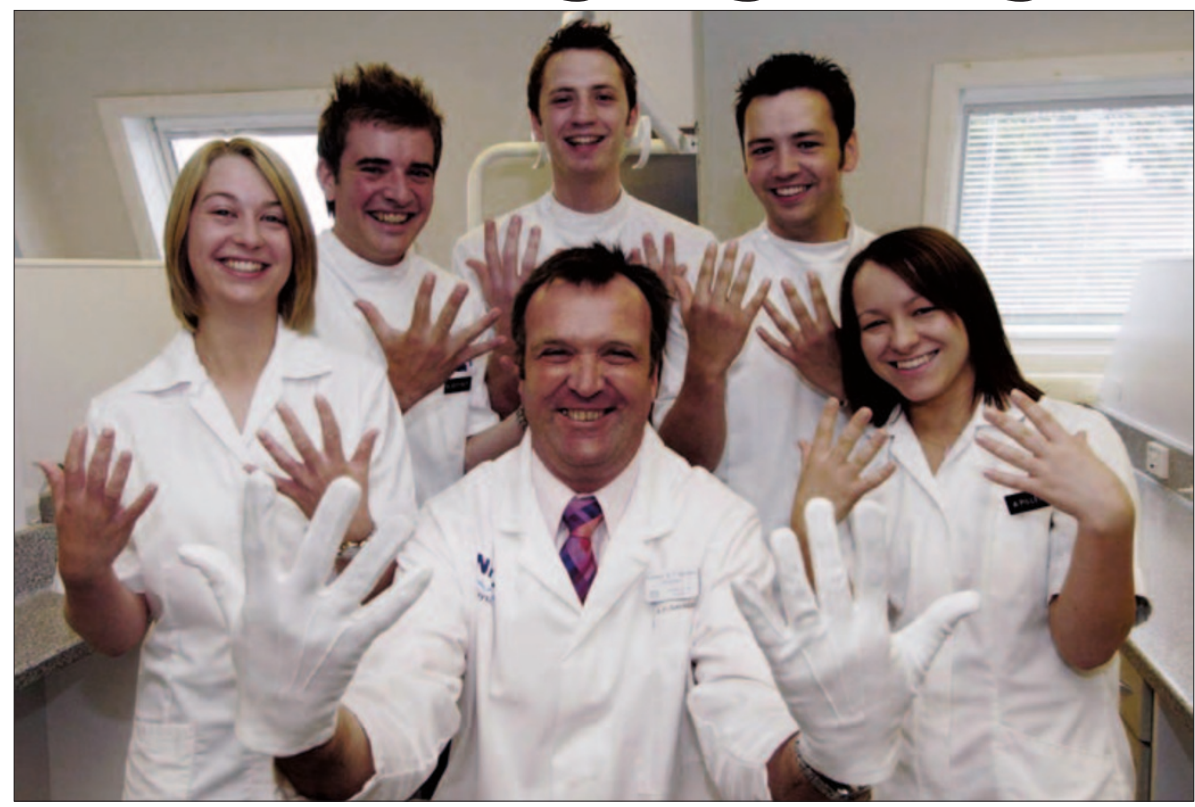

For the third year out of four, all the final year dental students at the University of Dundee passed with flying colours and presented the Dean with the traditional pair of white gloves, awarded when the whole year passes their exams. The Dean of Dentistry, Professor Bill Saunders (centre) was delighted to be presented with the gift again, a tradition which he is getting used to. Pictured left to right: Lorraine Mitchell from Forfar, Alban Higgins from Stirling, Andrew Jeffrey from Aberdeen, Jonathan McLean from Northern Ireland, and Angela Pilley from Dundee.

\title{
Survey says decay in children's teeth decreasing
}

Dental decay in children's permanent teeth has decreased to its lowest recorded level, according to a survey recently published by the Office for National Statistics.

The 2003 Children's Dental Health Survey found that obvious dental decay in eight, 12 and 15 year-old children's permanent teeth had decreased since 1983 and that the proportion of five and eightyear-olds with filled primary teeth had declined since 1983.

In both five and eight-year-olds, filled primary teeth represented a smaller proportion of the total obvious decay experience than in the previous surveys.

In 2003, $62 \%$ of 12 -year-olds and 50\% of 15-year-olds were free from any obvious decay experience in the permanent teeth. Among both 12 and 15-year olds $87 \%$ were free from cavities into dentine in the permanent teeth. The average number of permanent teeth with cavities into dentine or obvious decay experience among eight, 12 and 15-year-olds decreased between the 1993 and 2003 surveys. In 12 and 15 year-olds the average number of filled permanent teeth also decreased.

Following publication of the survey, the BDA has raised concerns over the lack of significant improvement in the percentage of five-year-olds suffering serious decay, though the oral health of older children has improved. It added that better education and information were key to tackling the continuing problems of dental disease and decay.

The survey was commissioned by the four UK Health Departments and is the fourth in a series of national dental health surveys carried out since 1973.

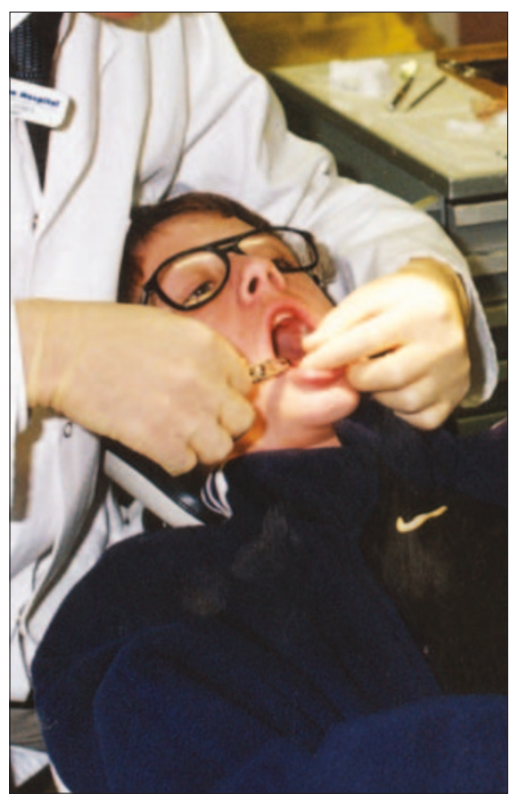




\section{DIARY}

August 2004

8th Congress of the International Congress of Oral Implantologists - Asia Pacific

Section \& International Symposium of the

Asian Oral Implant Academy

Date: 27-29.08.04

Venue: The New Otani, Singapore

Contact: Meeting secretariat

Tel: 67343162

Fax: 67321979

Email: singdent@singdent.com.sg http://web.singnet.com.sg/ qualiser/me eting.html

September 2004

IFEA Sixth Endodontic World Congress

Date: 8-11.09.04

Venue: Brisbane Convention and

Exhibition Centre, Queensland, Australia

Tel: (0)7 38585599

Email: ifea2004@im.com.au

www.ifea2004.im.com.au

92nd FDI World Dental Congress

Date: 10-13.09.04

Venue: Delhi, India

Tel: +91 1123315834

Email: shastri@tci.co.in

www.fdiworldental.org

Cleft care and the patient in the UK, Europe and Beyond

Date: 14.09.04

Venue: Royal Society of Medicine

Contact: Cleft Lip and Palate Association

Tel: +44 (0)2078334883

Email: info@clapa.com

www.clapa.com

\section{Clamping down on fraud}

A landmark agreement between the NHS and the Inland Revenue has been signed which aims to cut down fraud against the National Health Service (NHS).

It is hoped the "Memorandum of Understanding' (MoU) will strengthen the flow of information between the two services, enabling the quicker prosecution of fraudsters. Between 1999 and 2002, the NHS's counter fraud work cut dental patient fraud by 25\% and, in some areas, fraud by NHS professionals by $18-30 \%$.

According to the Counter Fraud Service, the agreement will be particularly effective in cases where patients are falsely claiming to be unemployed to escape any necessary charges, where staff members are claiming sick pay while undertaking other paid work illegally and where NHS staff are claiming for work they have not done.

Under the terms of the MoU, the Counter Fraud Service will be able to provide information to the Inland Revenue to help them pursue suspected tax fraud or significant tax evasion. The agreement details the information that can now be shared between the organisations, and the new systems for sharing it.

Information will be exchanged where there is a clear need to investigate a crime, with a range of safeguards to ensure that the exchange is lawful, secure and does not infringe human rights or the Data Protection Act.

\section{New appointment at Manchester}

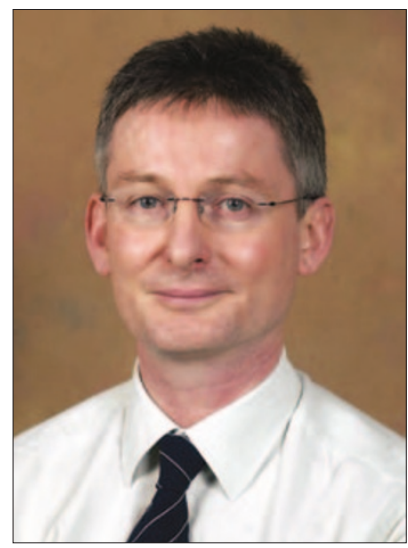

Professor Kevin 0’Brien has recently been appointed as Head of the School of Dentistry at the University of Manchester for five years.

He qualified from Manchester in 1979 and worked for several years in general dental practice, junior hospital posts and the orthodontic speciality training programme in Manchester

He has worked in the United States at the University of Pittsburgh and was appointed Professor of Orthodontics in 1995.

He has an international research profile and has published widely on orthodontic growth modification and clinical trials of orthodontic treatment methods. 